\title{
Successful Outcome of Pregnancy with Large Fibroid Uterus- A Case Report
}

\author{
NAHREEN AKHTAR ${ }^{1}$, SAYEEDA SULTANA ${ }^{2}$, FAHMIDAZABIN ${ }^{1}$
}

\begin{abstract}
:
Background:Fibroid is the most common of all pelvic tumours, being present in 20 percent of women in the reproductive age group and increases with age.Obstetric cesarean hysterectomy is mostly done for indications deemed to be serious and life threatening to the patient and not amenable to conservative management.
\end{abstract}

Case: A 27 years old lady was admitted in BSMMU with $3^{\text {rd }}$ gravida 35 wks pregnancy with less fetal movement with fibroid uterus. Fibroid was diagnosed at her 21 weeks pregnancy by ultrasonogram. Caesarean section was done at $35^{+}$weeks of pregnancy because of nonreactive CTG. After delivery of the baby and placenta, severe bleeding started. Caesarean hysterectomy was done. The mother and baby were healthy at the time of discharge.

Conclusion: Very few patients needed cesarean hysterectomy in case of fibroids in pregnancy. However there is no question that cesarean hysterectomy save lives especially in case of bleeding that cannot be controlled by simpler measures.

Key words: Fibroid uterus, caesarean hysterectomy

\section{Introduction:}

Fibroids are common benign growth of muscle fibre and fibrous tissues often found in uterus ${ }^{1}$. It is found in approx. $25 \%$ to $35 \%$ of reproductive age women. As more women choose to delay childbearing, issue of fibroids in pregnancy is likely to face with increasing frequency ${ }^{2}$.It may be found upto $4 \%$ of pregnancy 3,4 . Fibroids are slow to grow and it takes 3 years for one to reach the size of an orange. This, however, is only a generalization, the rate of growth varies from patient to patient and from time to time in same patient. There may be waves of growth interspersed with phases of quiescence and a degenerative change that can cause a rapid and gross enlargement of any tumour $^{5}$. Approx. $90 \%$ of fibroids do not appear to change in size during pregnancy ${ }^{6}$. The mean increase in fibroid volume during pregnancy is $12 \%$ \& few fibroid increase by more than than $25 \%{ }^{7}$. Growth of fibroids seems most likely to occur during thr first trimester in fibroids larger than $5 \mathrm{~cm}$ in diameter.Fibroid less than $5 \mathrm{~cm}$ in diameter tend to remain stable or decrease in size ${ }^{8}$. Fibroid in pregnancy is associated with an antepartum complications of $10 \%$ to $40 \%$. There is increased rate of caesarean section when fibroids are located in lower uterine segment ${ }^{9}$. Risk of postpartum haemorrhage $(\mathrm{PPH})$ in these women may be increased further by caesarean delivery by decreasing force and coordination of uterine contraction leading to uterine atony 10 .

\section{Case Report:}

A 27 years old lady ,P-1+1(ab) got admitted in BSMMU on $6^{\text {th }}$ April ' 08 with 35 wks pregnancy with less foetal movement and fibroid uterus. .She was on antenatal check up. At her 21 wks pregnancy, when anomaly scan was done, it shows a hypoechoic solid mass measuring about $(14.72 \times 13.47) \mathrm{cm}$ seen in anterior wall of lower part of the uterus. At her 31 wks of pregnancy she developed heaviness in lower abdomen. sensation of incomplete voiding of urine and occasional respiratory distress. At her 35 weeks of pregnancy she developed less foetal movement for 4 days and got admitted in BSMMU. After admission patient was clinically anaemic, height of uterus was 36 weeks, presentation was difficult to delineate. There were suprapubic bulging because of fibroid uterus. On two days after admission CTG was done and shows reduced acceleration.A decision for caesarean section was taken. After opening the abdomen, whole of the lower segment was occupied by the tumour

1. Assoc.Professor, Department of Obs \& Gynae, BSMMU

2. Assist Professor, Department of Obs \&Gynae, BSMMU 
With difficulty an incision was given high up above the tumour at the body of uterus. The baby was transversely placed and delivered by breech extraction.Placenta was also in the upper segment and delivered intact. Then severe bleeding started. So decision for total abdominal hysterectomy was taken.Uterus was so big with the tumour that it was very difficult to bring out the uterus. So we try to enucleate the tumour first. The lower limit of the tumour extend upto tne vagina. Tumour weighing about $5 \mathrm{~kg}$ was enucleated. Total abdominal hysterectomy was done.Finally urinary bladder was checked to see any injuiry occur during enucleation of tumour from vagina. Then abdomen was closed in layers keeping a drain tube. The patient was discharged on $8^{\text {th }}$ POD.

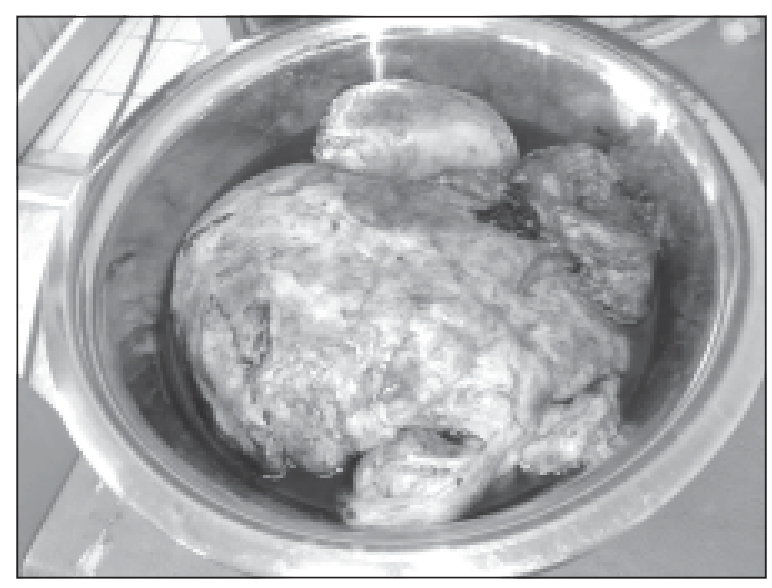

Fig 1: Pregnant uterus along with large fibroid

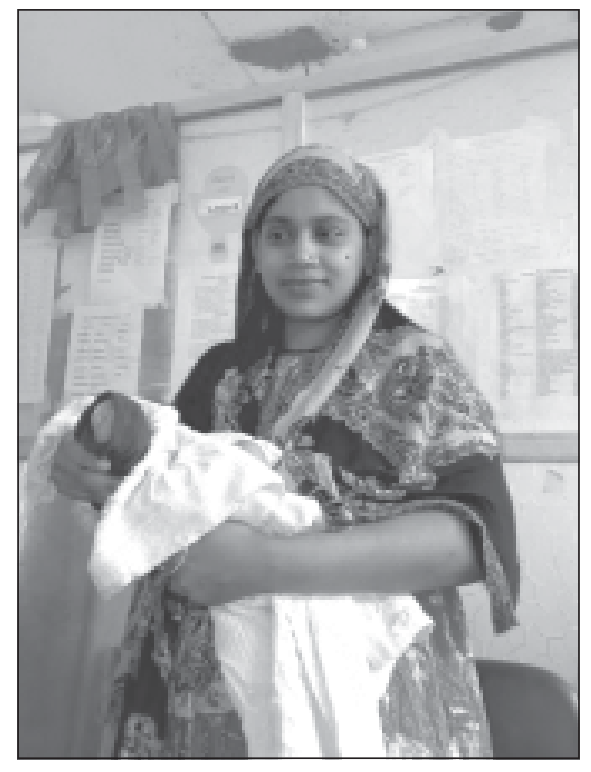

Fig 2: Pt and baby during discharge.

\section{Discussion:}

Fibroids are actually quite common- between $50 \%$ to $80 \%$ of all women have at atleast one. For the most part, these fibroids causes no symptoms, though they can be symptomatic for about $20 \%$ of women. Between $10 \%$ and $30 \%$ of pregnant women also have fibroids $^{11}$. Fibroids that change the shape of uterine cavity (submucous) decreases fertility by about $70 \%$ and removal of these fibroid growth probably depends on individual differences in genetic changes in each fibroid and the type of amount of growth factors that are present in the blood ${ }^{11}$. Some fibroids can affect fertility, pregnancy, and delivery of the baby. However, in the majority of cases, fibroids do not cause any major complications to the pregnancy or childbirth. An ultrasound study of pregnant women with fibroids found that $69 \%$ of the women had an increase in size of fibroids throughout the pregnancy ${ }^{12}$. In $31 \%$ of women who had an increase in size, it usually happened, before the third month.Almost always, fibroid shrink after delivery ${ }^{12}$. During pregnancy uterine fibroid are usually asymptomatic but may be occasionally complicated by red degeneration and an increased frequency of spontaneous abortion, preterm labour, premature rupture of fetal membranes, antepartum haemorrhage, malpresentation, obstructed labour, caesarean section and postpartum haemorrhage ${ }^{13}$.The management of uterine fibroid during pregnancy is largely expectant and its surgical removal is generally delayed until after delivery ${ }^{11}$. Because of the increased vascularisation of the uterus during pregnancy women are at increased risk of bleeding and postpartum morbidity during myomectomy and hysterectomy ${ }^{14}$. Some reports have shown that myomectomy during caesarean delivery can be safe ${ }^{15}$. In our case the fibroid occupies the whole lower segment and extend into vagina. The pregnancy was in upper segment of uterus. Because of large tumour here total abdominal hysterectomy (TAH ) was done and also to prevent postpartum haemorrhage. It is found that complications of elective caesarean section (C/S) and total abdominal hysterectomy rate was $12.8 \%$ and $13.4 \%$ respectively. The predictive combined complication rate for elective caesarean hysterectomy was much lower (16.1\%). The rate of transfusion was higher for caesarean hysterectomy (13.0\%) and that for C/S (0\%) and TAH (3.4\%) alone. In one study in Kashmir,they showed 146 cesarean hysterectomy in 
2 years time out of 10139 cesarean deliveries ${ }^{16}$. Out of which 1 patient need cesarean hysterectomy for fibroid uterus ${ }^{16}$. Reported incidence of cesarean hysterectomy is 5-8 per 1000 cesarean deliveries ${ }^{17}$. Although hysterectomy following section is probably easier than performing one later, but blood loss is greater about two to three times more. For this reason, most surgeons do not plan cesarean hysterectomy even when a women has other conditions that might require hysterectomy. Under certain condition planned hysterectomy may be appropriate ${ }^{18}$. Some patients have multiple large myomas that can obstruct the pelvic outlet. Others can experience painful degeneration of myomas or menorrhagia. Such patient are frequently best served by an operation that can accomplish both delivery and definitive treatment of their symptomatic myomas ${ }^{19}$. In one study over 5years time, they found incidence of fibroid with pregnancy was 1 in 800 confinements. They needed one cesarean hysterectomy for postpartum haemorrhage ${ }^{20}$.

\section{Conclusion:}

Fibroid in pregnancy is not very uncommon. Ultrasonography is helpful not only in diagnosing the presence of fibroid with pregnancy but also in finding out size, number and site of fibroids and their relation to the placenta. If it is in lower segment the myomectomy may have to done. So arrangement of blood and expert obstetrician should do the caesarean section in best place.

\section{References:}

1. Rice JP,Kay HH, Mahany BS. The clinical significance of uterine leiomyoma in pregnancy. Am J obstet gynecol 1989;160:1212-6.

2. Bultrum VC, Reiter RC. Uterine leiomyoma etiology, symptomatology and management. Fertile Sterile 1981;36:433-45.

3. Exacoustos C, Rosati P. Ultrasound diagnosis of uterine myomas and complications in pregnancy. Obstet Gynecol 1993, 82: 97-101.

4. Katz VL,Dotters DJ, Droegemuller W. Complications of uterine leiomyomas in pregnancy. Obstet gynecol 1989; 73:5936.PMID.

5. Kumar. Jeffecoate's Principle of Gynaecology.7th ed. New Delhi: Jaypee Brothers Medical publishers (P) Ltd ;2008. p. 490.
6. Muram D, Gilliason MS,Wakers JH. Myomas of uterus in preg, Ultrasonographic follow up. Am J Obstet Gynecol 1990; 138 : 16-9

7. Rosati P. J Ultrasound Med 1992 ; 11: 511 -5

8. Ouyang DW et at al.,Obstet complications of fibroids. Obstet Gynaecol Clin North Am. 2006; 33: 153-69. PMID.

9. Hassiakos D et al,. Myomectomy during cesarean section: a safe procedure? Ann N Y Acad Sci. 2006; 1092:408-13. PMID:

10. Kaymak $\mathrm{O}$ et al. Myomectomy during cesarean section. Int J Gynaecol Obstet.2005:89:903.PMID:

11. Pregnancy Complications:Uterine Fibroids During Pregnancy.http://www.pregnancy-info.net/ fibroids.htm1.

12. Fibroids Fertility and Pregnancy. http:// www.fibroids second opinion. com/ pregnancy.htm

13.. Brown D, Fletcher HM, Myric MO Reid M: Cesarean myomectomy a safe procedure. A retrospective case control study. Obstet Gynaecol !999;19:139-141.

14. Ehigiegba AE, Evbucmwan CE. Inevitable caesarean myomectomy. Trap J Obstet Gynaecol 1998; 5:62.

15. Micholas SP. Orcopoulok PV. Papageorigion Jobsted JS. Myomectomy during pregnancy and caesarean section, human reproduction 1995; 10: 1869-70.

16. S N Ahmad \& I H Mir. Emergency peripartum Hysterectomy: Experience at Apex Hospital of Kashmir Valley. The Internep J of Gynaecology and obstetrics 207;8(2): !SSN: 1528-2439.

17. Gabbe. Obstetrics: Normal and Problem pregnancies, $5^{\text {th }}$ ed Churchill Livingstone. 2007; 78: p153-4.

18. Labour and Delivery Complications of Cesarean Section. www health line.com/ pregnancy/ complications-cesarean section, html.

19. Grainger S Lanneau Jr. Cesarean Hysterectomy: Operative Obstetric.Global Library of Women Medicine. Washington 2008.

20. Shalish Kore. Anahita Pandole. J Obstet Gynecol Ind 2004; 54(4) :361-2. 